POPULATION STUDY ARTICLE

\title{
Independent and combined influence of healthy lifestyle factors on academic performance in adolescents: DADOS Study
}

\author{
Mireia Adelantado-Renau ${ }^{1}$, David Jiménez-Pavón ${ }^{2}$, Maria Reyes Beltran-Valls ${ }^{1}$ and Diego Moliner-Urdiales ${ }^{1}$
}

\begin{abstract}
BACKGROUND: Few studies have analyzed the combined effect of lifestyle factors on academic performance (AP) in adolescents. The aim of this study was to analyze the independent and combined effects of weight status, screen time, sleep quality, daily meal frequency, cardiorespiratory fitness, and physical activity (PA) on AP in adolescents.

METHODS: A total of 262 adolescents (13.9 0.3 years) from the DADOS study were included in the analysis. Weight status was assessed through body mass index $\left(\mathrm{kg} / \mathrm{m}^{2}\right)$. Participants completed questionnaires to evaluate screen time, sleep quality, and daily meal frequency. Cardiorespiratory fitness was assessed by the 20-m shuttle run test. PA was evaluated by a wrist-worn GENEActiv accelerometer. AP was assessed through the final academic grades and a validated questionnaire.

RESULTS: Non-overweight status, low screen time, good sleep quality, and proper meal frequency showed independent, positive influence on AP. Moreover, adolescents achieving at least three healthy lifestyles were more likely to be in the high-performance group for academic grades than those achieving $\leq 1$ (math OR: 3.02-9.51, language OR: 3.51-6.76, and grade point average OR: 4.22-9.36).

CONCLUSIONS: Although individual healthy lifestyles are independently and positively associated with AP, the cumulative effect of multiple healthy lifestyles have a stronger impact.
\end{abstract}

Pediatric Research (2019) 85:456-462; https://doi.org/10.1038/s41390-019-0285-z

\section{INTRODUCTION}

A healthy lifestyle during adolescence improves physical and cognitive health with potential benefits on academic performance (AP). ${ }^{1}$ AP refers to educational goals that students have to reach in a particular period of time, ${ }^{2}$ and is usually assessed through academic grades or using standardized tests of academic abilities or achievement. Although AP seems to be strongly related to cognition, it also involves non-cognitive skills such as motivation, effort, attitude, interest, family support, personality, or teaching influence. ${ }^{3}$ Successful AP during adolescence is considered a strong predictor of future health, wealth, employability, and social triumph. ${ }^{4,5}$

Prior research has widely analyzed the impact of healthy lifestyle factors on AP during childhood and adolescence. ${ }^{1}$ For instance, high screen time or an overweight and obesity status have been related to several brain areas with impairments in cognition and associated with lower school performance. ${ }^{6-8}$ On the other hand, proper sleep has shown to improve brain plasticity and memory consolidation ${ }^{9}$ leading to better AP in children and adolescents. ${ }^{10}$ Following adequate dietary patterns, such as regular five-meal-a-day or not skipping breakfast has also been related to high school performance in this age population. ${ }^{11}$ Results from recent reviews suggest that high levels of physical fitness, particularly cardiorespiratory fitness (CRF), might positively influence adolescents' AP by altering brain structure, plasticity and improving attention, memory and cognitive function. ${ }^{12}$ In accordance, scientific literature examining the relationship between physical activity (PA) and AP has stated that PA increases concentration, self-esteem, and self-discipline with improvements in academic performance indicators. ${ }^{12,13}$
Interestingly, it has been previously suggested that individual healthy lifestyles may not act in isolation in their influence on AP. ${ }^{1}$ However, to date only three studies have examined the combined effect of multiple healthy lifestyle factors on AP in children ${ }^{14,15}$ and adolescents $^{16}$ showing a positive relationship. Although previous research also included a wide range of healthy lifestyle factors, it would be interesting to include objective measures of physical activity (i.e., accelerometry), valid measures of sleep, or an overall academic performance measurement. Therefore, given the paucity of knowledge and the need for valid and objective lifestyle measurements, more studies are necessary to clarify the cumulative effect of a cluster of healthy lifestyles on AP in adolescents, which would help to design more effective schoolbased programs to improve AP.

Thus, the aim of the present study was to analyze the independent and combined effect of healthy lifestyle factors (i.e., weight status, screen time, sleep quality, daily meal frequency, CRF, and PA) on AP in adolescents.

\section{METHODS}

Study design and sample selection

This study is part of the DADOS (Deporte, ADOlescencia y Salud) research project, a 3-year longitudinal study aimed to analyze the influence of PA on health, AP, and psychological wellness through adolescence. All participants were recruited from secondary schools located in Castellon (Spain) and met the general DADOS inclusion criteria: born in 2001, enrolled in second grade of secondary school and free of any chronic disease. The results

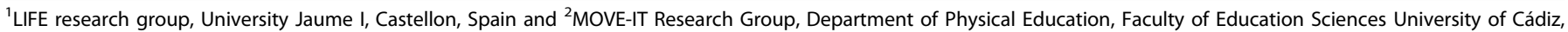
Cádiz, Spain

Correspondence: Diego Moliner-Urdiales (dmoliner@uji.es)

Received: 14 August 2018 Revised: 8 November 2018 Accepted: 30 December 2018

Published online: 17 January 2019 
presented in this study belong to baseline data obtained between February and May of 2015. A total of 262 adolescents aged $13.9 \pm$ 0.3 years ( $48 \%$ girls) completed the baseline assessment with valid data for weight status, screen time, sleep quality, daily meal frequency, CRF, PA, and AP.

Adolescents and their parents or guardians were informed of the nature and characteristics of the study, and all provided a written informed consent. The DADOS study protocol was designed in accordance with the ethical guidelines of the Declaration of Helsinki 1961 (last revision of Fortaleza, Brazil, 2013) and approved by the Research Ethics Committee of the University Jaume I of Castellon (Spain).

Healthy lifestyle factors

Body weight status. Measures of weight and height were assessed in duplicate by trained members of the DADOS research group following standardized procedures. ${ }^{17}$ Body mass index (BMI) was calculated as weight/height square $\left(\mathrm{kg} / \mathrm{m}^{2}\right)$. Participants were classified into normal weight and overweight or obese, according to the international age- and sex-specific BMI cutoffs proposed by Cole et al. $^{18}$

Screen time. Screen time was assessed using the HELENA (Healthy Lifestyle in Europe by Nutrition in Adolescence) sedentary questionnaire, designed ad hoc. ${ }^{19}$ For both, weekdays and weekend days, adolescents reported the number of hours spent on television, videogames, internet and mobile phone. Seven possible answers were available for each item: no time, $<30 \mathrm{~min}, \geq 30$ to $<60 \mathrm{~min}, \geq 1$ to $<2 \mathrm{~h}, \geq 2$ to $<3 \mathrm{~h}, \geq 3$ to $<4 \mathrm{~h}$, and $\geq 4 \mathrm{~h}$. Total screen time for weekend and weekdays was calculated adding the mean time of each screen-based activity. The overall time was established as follows: $1 / 7 \times(2 \times$ weekend day $+5 \times$ weekday), and participants under the sex-specific 25th percentile were categorized as low screen time.

Sleep quality. Sleep quality was assessed through the Spanish version of Pittsburgh Sleep Quality Index (PSQI) questionnaire. ${ }^{20}$ It includes 19 questions that assess 7 components of sleep quality: subjective sleep quality, sleep duration, sleep latency, habitual sleep efficiency, sleep disturbance, use of sleep medication, and daytime dysfunction. The 7 component scores are rated on a 3-point ascending scale. The global score of the PSQI (Cronbach's $a=0.81$ ) was used in the analysis as the sum of all component scores ranging from 0 to 21 . According to Buysse et al. the PSQI questionnaire provides a sensitive measure to identify good sleep quality if total PSQI score is $\leq 5 .^{21}$

Daily meal frequency. Daily meal eating frequency was assessed through the question "Do you usually have the following meals?: (1) breakfast, (2) morning snack, (3) lunch, (4) afternoon snack, and (5) dinner". Possible answers for each meal were dichotomous (yes/no), and the number of meals per day was calculated by adding affirmative answers, with a final score ranging from 0 to 5 . According to Jääskeläinen et al., ${ }^{22}$ five-meal-a-day was considered as the optimal daily meal frequency pattern.

Cardiorespiratory fitness. CRF was assessed using the 20-m Shuttle Run Test as described by Léger et al. ${ }^{23}$ The final score computed as the number of stages completed (precision of 0.5 stages) was used in the analyses. Participants with CRF $\geq$ sexspecific 75th percentile were categorized as high CRF.

Physical activity. Levels of PA were objectively measured using the GENEActiv accelerometer. This device provides a reliable (coefficient of variation intra- and inter-instrument of $1.4 \%$ and $2.1 \%$, respectively $)^{24}$ and valid assessment of PA in young people $(r=0.925, p=0.001) .{ }^{25}$ Participants were instructed to wear the accelerometer on their non-dominant wrist for at least 6 consecutive days (including sleeping and water-based activities). At least 4 complete days including 2 weekend days were included in the analysis. Accelerometers were programmed to collect data at a sampling frequency of $100 \mathrm{~Hz}$ and stored in gravity (g) units. The raw acceleration output was aggregated in 1-s epochs using the GENEActiv postprocessing PC software (version 2.2; GENEACtiv). By combining all registered days for each participant and using the Excel macro provided by the commercial brand to summarize the data, PA was expressed as average minutes per day in light, moderate, and vigorous PA. Participants with vigorous $P A \geq$ sex-specific 75 th percentile were categorized as high vigorous $P A$.

Healthy lifestyle index. A healthy lifestyle index ranging from 0 to 6 was specifically defined for our sample according to the number of factors fulfilled by each adolescent: (1) optimal weight status (non-overweight or non-obese); (2) low screen time; (3) good sleep quality; (4) optimal daily meal frequency; (5) high levels of CRF, and (6) high levels of vigorous PA.

\section{Academic performance}

AP was assessed by two components: academic grades and a standardized test of academic abilities. The final academic grades from the 1st course of secondary school were provided by each school's secretary office on a ten-point scale. Individual grades for math and language, and grade point average (GPA) were used in the analyses. GPA was defined as the single average for geography and history, natural science, math, Spanish, Catalan, English, and physical education. In addition, participants completed the Spanish version of Science Research Associates Test of Educational Abilities which evaluates three basic skills: verbal ability (command of language), numeric ability (speed and precision in performing operations with numbers and quantitative concepts), and reasoning ability (aptitude to find logical ordination criteria in sets of numbers, figures, or letters). This battery test provides three complexity levels based on the age range of the sample. The present study used level three, which is designed for adolescents aged 14-18 years. This test was performed in a limited time period: $10 \mathrm{~min}$ for 2 activities of verbal ability, $11 \mathrm{~min}$ for 1 activity of numeric ability, and $6 \mathrm{~min}$ for 1 activity of reasoning ability. The alpha scores for its reliability have been reported to be 0.74 for verbal ability, 0.87 for numerical ability, and 0.77 for reasoning ability ${ }^{26}$ Participants were classified in high AP ( $\geq 50$ th of the median) and low AP ( $<50$ th of the median) for each AP indicator.

\section{Covariates}

Pubertal stage. Pubertal stage was self-reported according to the five stages defined by Tanner and Whitehouse. ${ }^{27}$ It is based on external primary and secondary sexual characteristics, which are described by the participants using standard pictures according to Tanner instructions.

Socioeconomic status. The Family Affluence Scale (FAS) developed by Currie and collaborators ${ }^{28}$ was used as a proxy of socioeconomic status (SES; ranging from 0 to 8 ), which is based on material conditions in the family such as car ownership, bedroom occupancy, computer ownership, and home internet access.

\section{Statistical analysis}

Study sample characteristics are presented as mean \pm standard deviation (SD) and percentages for continuous and categorical variables. All variables were checked for normality using both graphical (normal probability plots) and statistical (Kolmogorov-Smirnov test) procedures. As preliminary analyses did not show a significant interaction of sex with the study variables in relation to AP (all $p>0.10$ ), all analyses were performed with the total sample. 
Sex differences were assessed using $t$-test for continuous variables and chi-square test for nominal variables. The independent associations between individual healthy lifestyle factors and AP using dichotomized variables were analyzed by binary logistic regression adjusting for sex, pubertal stage, and SES.

One-way analysis of covariance (ANCOVA), with a Bonferroni post hoc test, was used to investigate whether AP indicators differed depending on the number of healthy lifestyle factors achieved. The analyses were adjusted for sex, pubertal stage, and SES. Additionally, logistic regression was conducted to examine the likelihood of achieving high AP depending on the number of healthy lifestyle factors achieved, after adjustment for sex, pubertal stage, and SES. For these analyses, the following categories of achieved healthy lifestyle factors (independent variable) were used: $\leq 1,2,3,4$, and $\geq 5$. Logistic regression analyses were repeated using a dichotomous independent variable according to the number of achieved healthy lifestyle factors ( $\leq 3$ vs. $\geq 4)$. All the analyses were performed using the IBM SPSS Statistics for Windows version 22.0 (Armonk, NY: IBM Corp), and the level of significance was set to $p<0.05$.

\section{RESULTS}

Descriptive characteristics of the study population by sex are presented at Table 1. Overall, boys were taller, showed better sleep quality (4.2 vs. $5.5 ; p \leq 0.001)$, higher meal frequency (4.6 vs. 4.4; $p<0.05)$, higher CRF $(9.0$ vs. $6.2 ; p<0.001)$ and were more physically active than girls according to moderate and vigorous PA (all $p \leq 0.001$ ). Boys and girls did not significantly differ in weight status and screen time ( 20.0 vs $20.6 \mathrm{~kg} / \mathrm{m}^{2}$, and 4.7 vs. $5.0 \mathrm{~h} / \mathrm{day}$; all $p>0.05)$. Regarding AP, no differences were found between boys and girls, except for numeric ability that was better in boys (14.8 vs. $12.0 ; p \leq 0.001$ ).

The independent associations of individual healthy lifestyle factors with AP are shown in Table 2. Non-overweight, low screen time ( $<25$ th percentile), good sleep quality (PSQI scores $\leq 5$ ), and optimal daily meal frequency (five-meal-a-day) were positively associated with likelihood of achieving high academic grades ( $\geq 50$ th of the median) after adjusting for sex, pubertal stage, and SES. Regarding academic abilities, non-overweight or non-obese adolescents had 3.17 times the odds of achieving high numeric ability.

Figure 1 shows the differences in AP indicators according to the healthy lifestyle index, after adjustment for sex, pubertal stage, and SES. Overall, adolescents with a healthy lifestyle index $\geq$ 4 showed higher academic grades than those with a healthy lifestyle index $\leq 2$.

The combined effect of weight status, screen time, sleep quality, daily meal frequency, CRF, and vigorous PA on AP is shown in Table 3. Logistic regression analysis showed that adolescents with a healthy lifestyle index $\geq 3$ were more likely to be in the highperformance group for academic grades. In terms of odds ratios, adolescents with a healthy lifestyle index $\geq 5$ were $9.51,6.76$, and 9.36 times more likely of achieving high academic grades in math, language and GPA, respectively. The association of healthy lifestyle index and academic abilities was only significant for reasoning with a healthy lifestyle index of $3(\mathrm{OR}=2.85 ; 95 \% \mathrm{Cl}=1.17-6.92)$, and for numeric ability with a healthy lifestyle index of $4(\mathrm{OR}=3.05$; $95 \% \mathrm{Cl}=1.15-8.10)$. Results from logistic regression analysis using a dichotomous healthy lifestyle index ( $<4$ vs. $\geq 4)$ are illustrated in Fig. 2. Similarly, adolescents with a healthy lifestyle index $\geq 4$ were more likely to show higher academic grades (OR: 2.08-2.25).

\section{DISCUSSION}

This study supports prior research by confirming the independent, positive influence of non-overweight and non-obese status, low screen time, good sleep quality and proper meal frequency on high $\mathrm{AP}$ in adolescents. In addition, our results show that
Table 1. Descriptive characteristics for the study sample

\begin{tabular}{|c|c|c|c|c|}
\hline & All & Boys & Girls & $p$ \\
\hline$n(\%)$ & $262(100)$ & $137(52.3)$ & 125 & \\
\hline \multicolumn{5}{|l|}{ Demographics } \\
\hline Age (y) & $13.9 \pm 0.3$ & $13.9 \pm 0.3$ & $13.9 \pm 0.3$ & 0.956 \\
\hline $\begin{array}{l}\text { Tanner stage } \\
(\mathrm{I}-\mathrm{V})(\%)\end{array}$ & 0/8/34/49/9 & $\begin{array}{l}0 / 10 / 32 / 44 / \\
14\end{array}$ & $0 / 6 / 35 / 54 / 5$ & - \\
\hline SES score $(0-8)$ & $4.2 \pm 1.4$ & $4.0 \pm 1.3$ & $4.4 \pm 1.4$ & 0.031 \\
\hline \multicolumn{5}{|l|}{ Weight status } \\
\hline Height $(\mathrm{cm})$ & $163.1 \pm 7.9$ & $164.7 \pm 8.6$ & $161.4 \pm 6.7$ & $<0.001$ \\
\hline Weight (kg) & $54.2 \pm 9.3$ & $54.5 \pm 9.7$ & $53.9 \pm 8.8$ & 0.574 \\
\hline $\begin{array}{l}\text { Body mass index } \\
\left(\mathrm{kg} / \mathrm{m}^{2}\right)\end{array}$ & $20.3 \pm 2.7$ & $20.0 \pm 2.6$ & $20.6 \pm 2.9$ & 0.053 \\
\hline Overweight (\%) & 13.0 & 11.7 & 14.4 & 0.513 \\
\hline Screen time ( $\mathrm{h} /$ day) & $4.8 \pm 2.5$ & $4.7 \pm 2.5$ & $5.0 \pm 2.6$ & 0.299 \\
\hline $\begin{array}{l}\text { Sleep quality score } \\
(0-21)\end{array}$ & $4.8 \pm 2.8$ & $4.2 \pm 2.7$ & $5.5 \pm 2.7$ & $<0.001$ \\
\hline $\begin{array}{l}\text { Good sleep quality } \\
\text { (\%) }\end{array}$ & 64.1 & 73.7 & 53.6 & $<0.001$ \\
\hline $\begin{array}{l}\text { Daily meal } \\
\text { frequency (meals/ } \\
\text { day) }\end{array}$ & $4.5 \pm 0.8$ & $4.6 \pm 0.8$ & $4.4 \pm 0.9$ & 0.014 \\
\hline $\begin{array}{l}\text { Optimal daily meal } \\
\text { frequency (\%) }\end{array}$ & 58.0 & 67.2 & 47.9 & 0.002 \\
\hline CRF (stages) & $7.7 \pm 2.5$ & $9.0 \pm 2.0$ & $6.2 \pm 2.2$ & $<0.001$ \\
\hline \multicolumn{5}{|l|}{$\begin{array}{l}\text { Physical activity } \\
\text { (min/day) }\end{array}$} \\
\hline Light & $174.6 \pm 56.4$ & $173.7 \pm 59.1$ & $175.6 \pm 53.4$ & 0.781 \\
\hline Moderate & $76.7 \pm 25.6$ & $81.6 \pm 24.8$ & $71.2 \pm 25.4$ & $<0.001$ \\
\hline Vigorous & $12.4 \pm 8.3$ & $15.6 \pm 7.8$ & $8.9 \pm 7.6$ & $<0.001$ \\
\hline \multicolumn{5}{|c|}{ Academic grades (1-10) } \\
\hline Math & $6.9 \pm 1.6$ & $7.0 \pm 1.6$ & $6.8 \pm 1.6$ & 0.316 \\
\hline Language & $6.8 \pm 1.5$ & $6.6 \pm 1.5$ & $6.9 \pm 1.5$ & 0.123 \\
\hline GPA & $7.1 \pm 1.3$ & $7.0 \pm 1.3$ & $7.2 \pm 1.3$ & 0.306 \\
\hline \multicolumn{5}{|l|}{ Academic abilities } \\
\hline Verbal (0-50) & $18.7 \pm 5.3$ & $19.1 \pm 5.8$ & $18.2 \pm 4.6$ & 0.154 \\
\hline Numeric $(0-30)$ & $13.4 \pm 4.7$ & $14.8 \pm 4.5$ & $12.0 \pm 4.5$ & $<0.001$ \\
\hline Reasoning $(0-30)$ & $16.5 \pm 5.9$ & $16.1 \pm 5.7$ & $17.0 \pm 6.1$ & 0.220 \\
\hline
\end{tabular}

Data are presented as mean \pm SD or percentages. Differences between sexes were examined by $t$ test or chi-square test. Statistically significant values are in bold

SES socioeconomic status, CRF cardiorespiratory fitness, GPA grade point average

ancludes obese adolescents. Good sleep quality was defined as PSQI scores $\leq 5$. Optimal daily meal frequency was defined as five-meal-a-day

academic grades are higher in adolescents with a healthy lifestyle index $\geq 4$ comparing with those achieving $\leq 2$ healthy lifestyle factors. The main finding of the present study reveals that the combined effect of a cluster of healthy lifestyle factors (healthy lifestyle index) including non-overweight or non-obese status, low screen time, good sleep quality, optimal daily meal frequency, high CRF, and high vigorous PA had a stronger impact on AP than their respective individual effects.

In the present study, healthy lifestyle factors showed independent and combined associations with academic grades, but not with academic abilities. These divergent results for academic performance indicators may be partially explained by several issues: (1) academic grades represent the student progression over a whole school year, while academic abilities are measurements from standardized tests which assess specific abilities in a 
Table 2. Logistic regression analyses examining independent influence of healthy lifestyle factors on academic performance in adolescents $(n=262)$

\begin{tabular}{|c|c|c|c|c|c|c|c|}
\hline & & $\begin{array}{l}\text { Academic } \\
\text { grades }\end{array}$ & & & $\begin{array}{l}\text { Academic } \\
\text { abilities }\end{array}$ & & \\
\hline & & Math & Language & GPA & Verbal & Numeric & Reasoning \\
\hline & Non-overweight & $\begin{array}{l}3.09 \\
(1.40-6.80)\end{array}$ & $\begin{array}{l}2.77 \\
(1.27-6.05)\end{array}$ & $\begin{array}{l}2.45 \\
(1.14-5.30)\end{array}$ & $1.92(0.91-4.02)$ & $\begin{array}{l}3.17 \\
(1.44-6.97)\end{array}$ & $\begin{array}{l}1.70 \\
(0.80-3.58)\end{array}$ \\
\hline Screen time & High & 1 (ref.) & 1 (ref.) & 1 (ref.) & 1 (ref.) & 1 (ref.) & 1 (ref.) \\
\hline \multirow[t]{2}{*}{ Sleep quality } & Poor & 1 (ref.) & 1 (ref.) & 1 (ref.) & 1 (ref.) & 1 (ref.) & 1 (ref.) \\
\hline & Good & $\begin{array}{l}1.80 \\
(1.06-3.07)\end{array}$ & $\begin{array}{l}1.88 \\
(1.11-3.20)\end{array}$ & $\begin{array}{l}1.83 \\
(1.02-1.47)\end{array}$ & $0.90(0.53-1.52)$ & $1.35(0.79-2.30)$ & $\begin{array}{l}0.96 \\
(0.57-1.62)\end{array}$ \\
\hline \multirow[t]{2}{*}{ Daily meal frequency } & Poor & 1 (ref.) & 1 (ref.) & 1 (ref.) & 1 (ref.) & 1 (ref.) & 1 (ref.) \\
\hline & Optimal & $\begin{array}{l}1.94 \\
(1.11-3.40)\end{array}$ & $\begin{array}{l}2.41 \\
(1.37-4.23)\end{array}$ & $\begin{array}{l}2.53 \\
(1.43-4.48)\end{array}$ & $1.13(0.66-1.95)$ & $1.28(0.74-2.24)$ & $\begin{array}{l}1.32 \\
(0.76-2.28)\end{array}$ \\
\hline \multirow{2}{*}{$\begin{array}{l}\text { Vigorous physical } \\
\text { activity }\end{array}$} & Low & 1 (ref.) & 1 (ref.) & 1 (ref.) & 1 (ref.) & 1 (ref.) & 1 (ref.) \\
\hline & High & $1.52(0.85-2.72)$ & $1.25(0.71-2.21)$ & $1.34(0.75-2.38)$ & $1.45(0.81-2.58)$ & $1.28(0.71-2.32)$ & $\begin{array}{l}1.10 \\
(0.62-1.95)\end{array}$ \\
\hline \multicolumn{8}{|c|}{$\begin{array}{l}\text { Odds ratio ( } 95 \% \text { Confidence Intervals) above represents increased odds of achieving high AP ( } \geq 50 \text { th of the median). Analyses were adjusted for sex, puberta } \\
\text { stage, and socioeconomic status. Statistically significant values are in bold } \\
\text { GPA grade point average } \\
\text { alncludes obese adolescents. Low screen time was calculated as }<\text { the } 25 \text { th sex-specific percentile. Good sleep quality was defined as PSQI scores } \leq 5 \text {. Optima } \\
\text { daily meal frequency was defined as five-meal-a-day. High levels of cardiorespiratory fitness and vigorous physical activity were defined as } \geq 75 \text { th sex-specif } \\
\text { percentile }\end{array}$} \\
\hline
\end{tabular}
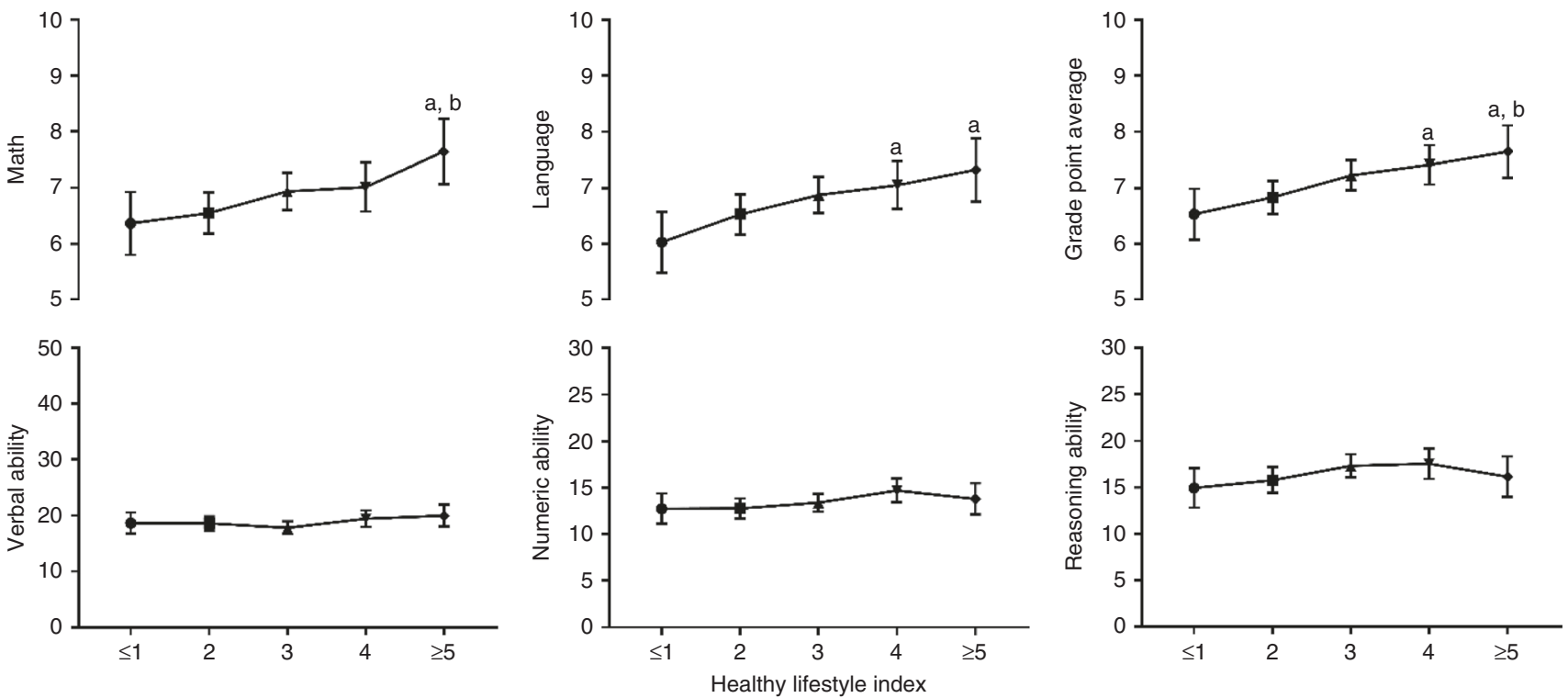

Fig. 1 Differences in academic performance indicators according to the healthy lifestyle index using ANCOVA, after adjustment for sex, pubertal stage, and socioeconomic status. Estimated marginal means with their $95 \%$ Confidence Intervals are presented. $\leq 1(n=31), 2$ $(n=69), 3(n=85), 4(n=49)$, and $\geq 5(n=28)$. "a" indicates significant differences $(p<0.05)$ with the first group (healthy lifestyle index $\leq 1)$; " $\mathrm{b}$ " indicates significant differences $(p<0.05)$ with the second group (healthy lifestyle index $=2$ )

single time point; (2) unlike academic abilities' test, which mainly requires good cognitive skills, the multidimensional nature of academic grades also involves emotional and social factors (i.e., effort, teacher influence, attitude) ${ }_{i}^{3}$ (3) academic grades, but not abilities, have shown to be determinant for college selection and admission, ${ }^{4}$ which might increase adolescents' motivation and effort to achieve higher grades; and (4) it is likely that teachers assign better grades to healthier adolescents because of their higher school attendance and commitment to long-term educational goals. 5,29

The results about the independent associations of the studied healthy lifestyle factors with AP in adolescents concur with 
Table 3. Logistic regressions analyses examining the combined effect of healthy lifestyle factors on academic performance $(n=262)$

\begin{tabular}{|c|c|c|c|c|c|c|}
\hline & \multicolumn{3}{|l|}{ Academic grades } & \multicolumn{3}{|l|}{ Academic abilities } \\
\hline & Math & Language & GPA & Verbal & Numeric & Reasoning \\
\hline \multicolumn{7}{|c|}{ Healthy lifestyle index } \\
\hline 2 & $1.70(0.68-4.26)$ & $1.96(0.78-4.91)$ & $2.68(1.03-6.97)$ & $0.91(0.38-2.18)$ & $1.21(0.50-2.95)$ & $1.27(0.53-3.09)$ \\
\hline 3 & $3.02(1.22-7.48)$ & 3.51 (1.41-8.77) & $4.22(1.63-10.89)$ & $0.85(0.36-2.01)$ & $2.26(0.93-5.46)$ & $2.85(1.17-6.92)$ \\
\hline
\end{tabular}

Odds ratio (95\% Confidence Intervals) above represents increased odds of achieving high AP ( $\geq 50$ th of the median). Analyses were adjusted for sex, pubertal stage, and socioeconomic status. Statistically significant values are in bold. $\leq 1(n=31), 2(n=69), 3(n=85), 4(n=49)$, and $\geq 5(n=28)$ GPA grade point average

\begin{tabular}{lllll}
\hline Academic grades \\
Math \\
Language \\
Grade point average
\end{tabular}

Fig. 2 Logistic regression model predicting high academic performance ( $\geq 50$ th of the median) according to the healthy lifestyle index ( $<4$ vs. $\geq 4$ ). Analysis adjusted for sex, pubertal stage, and socioeconomic status. OR odds ratio, $\mathrm{Cl}$, confidence intervals. Reference $(\mathrm{OR}=1.00)$ : adolescents with a healthy lifestyle index $<4(n=185)$

previous research showing that non-overweight status, ${ }^{30}$ low screen time, ${ }^{31}$ good sleep quality, ${ }^{10}$ and optimal daily meal frequency ${ }^{11}$ were independently and positively associated with AP. Conversely, CRF and vigorous PA were not independently associated with AP.

The association between weight status and AP might be partially explained by psychological and behavioral disturbances (e.g., isolation, bullying, low self-confidence) common in obese children and adolescents. ${ }^{32}$ In addition, overweight-derived health problems may increase school absenteeism, ${ }^{29}$ while other related behaviors (e.g., poor sleep, unhealthy dietary patterns, low levels of PA) could also negatively influence academic results. ${ }^{2,30}$ Regarding screen time, our findings could be partially explained by the hypotheses of time and energy displacement which suggests that screen time replaces other activities such as verbal interaction or sleep, with adverse consequences over $\mathrm{AP}^{33}$ Interestingly, prior research revealed that screen time for entertainment, particularly internet usage, was negatively related with AP in adolescents, but positively associated when used for educational purposes, ${ }^{34}$ highlighting the importance of the usage purpose when analyzing screen-based activities. Concerning sleep, previous scientific evidence suggested that poor sleep quality was associated with sleepiness, which may have negative effects on attention, memory and learning abilities. ${ }^{9}$ Finally, with respect to the regular consumption of five-meal-a-day, the facilitated blood glucose response after each meal might help cognitive processes with improvements in academic results. ${ }^{1,35}$ In addition, prior literature suggested that food insecurity (i.e., insufficient financial resources to access to a varied and balanced diet) may lead to irregular meal patterns and insufficient nutrients intake, negatively influencing physical and mental health (i.e., psychological and emotional well-being), which in turn, might affect alertness, school attendance, and achievement. ${ }^{36}$

Although CRF and vigorous PA showed no association with AP on an individual level, recent literature has stated multiple benefits of high levels of CRF and vigorous PA on AP, ${ }^{12,13}$ which are related with changes in brain structure and function, ${ }^{37}$ as well as with better cognitive skills. ${ }^{38}$ Thus, since healthy lifestyle factors seem not to act in isolation, it is likely that on a combined level, both factors may contribute to AP. Therefore, these factors were included in the healthy lifestyle index to examine combined associations.

The combined effect analysis revealed that adolescents with a healthy lifestyle index $\geq 4$ showed higher scores in academic grades compared with those with an index $\leq 2$. Moreover, adolescents with a healthy lifestyle index $\geq 3$ had increased likelihood of achieving high AP. To date only three studies have analyzed the combined influence of diverse health-related factors on AP; ${ }^{14-16}$ however, none of them has investigated the influence of the six healthy lifestyle factors included in this study. MartínezGómez et al. ${ }^{16}$ noted similar results in a sample of 1825 Spanish adolescents - girls meeting 3 or 4 recommendations for health behaviours including indicators of PA, television viewing, sleep duration and fruit consumption, were 1.75 and 3.18 times more likely to achieve better results in math and language respectively, compared with those meeting 0-1 health behaviours. Another study performed in the United States, analyzed 14 "health assets" (related to weight status, physical fitness, diet, PA, screen time, smoking, well-being, and sleep quality) concluding that children fulfilling more health recommendations were more likely to achieve goals for math, reading and writing. ${ }^{15}$ In a recent study, Faught et al. found that children fulfilling from 7 to 9 lifestyle 
recommendations (including PA, television viewing, sleep duration and 6 items related to dietary patterns) showed higher odds of achieving better results for math, reading and writing. ${ }^{14}$ Our results could be explained by the cumulative effect of each individual healthy lifestyle factor on AP. The reasons underlying the positive relationship between these factors and AP cannot be elucidated in the current study. However, a possible explanation could be that the cumulative effect of the factors included in the healthy lifestyle index might improve attention, concentration, memory, and cognitive functioning, which, in turn, may result in higher academic outcomes in adolescents.

An important question to mention is the possible reverse causation. Academic success could also positively influence health status by improving adolescents' knowledge about healthy lifestyles, as well as, psychological (e.g., self-esteem, personal control) and social aspects. ${ }^{39}$ Therefore, further longitudinal studies are needed to shed light on the bidirectional relationship between healthy lifestyles and AP in adolescents.

\section{Strengths and limitations}

Unfortunately, the cross-sectional design of the present study does not allow us to establish causal relationships. A second limitation was the use of self-reported data (i.e., screen time, sleep quality, and daily meal frequency). The properties of self-reported health information in adolescents have been poorly examined; nonetheless, self-reported measures related to non-compromising topics have demonstrated good reliability. ${ }^{40}$ Moreover, the present study did not include measures of nutritional status, using daily meal frequency as a proxy of regular meal pattern. Additionally, most of the participants were physically active, which could limit the generalizability of our findings to other populations. Finally, the use of a standardized test of academic abilities, and academic grades, although socially valid measures of AP, can be subject to biases. This study have several strengths such as the relatively large and age-matched sample of adolescents (13.9 \pm $0.3 \mathrm{y})$, the use of validated and standardized tests to assess weight status, sleep quality, CRF and academic abilities, and the inclusion of objective measures of PA by accelerometry. In addition, the statistical analyses were controlled for SES which is relevant given its relation with health status ${ }^{41}$ and academic performance. ${ }^{2}$

\section{CONCLUSIONS}

In summary, the results of our study suggest that although individual healthy lifestyle factors are independently and positively associated with $\mathrm{AP}$, the cumulative effect of multiple healthy lifestyle factors has a stronger impact on AP. Our findings are of paramount importance because of the key role of AP on future work achievement ${ }^{4}$ and health status. ${ }^{5}$ Health and education professionals could benefit from collaborating to achieve both improved health status, and academic performance. Further prospective research analyzing the combined effect of several healthy lifestyles on cognition in different specific populations are needed for a better understanding of the mechanisms involved.

\section{ACKNOWLEDGEMENTS}

The DADOS Study is funded by the Spanish Ministry of Economy and Competitiveness, MINECO (DEP2013-45515-R) and by the Jaume I University of Castellon, UJ (P1-1A2015-05). This work is partly supported by a Sunny Sport research grant from the Schweppes Suntory Spain Company. D.J.P. was supported by a grant from the Spanish Ministry of Science and Innovation - MINECO (RYC-2014-16938). M.A.R. is supported by a Predoctoral Research Grant from UJI (PREDOC/2015/13).

\section{AUTHOR CONTRIBUTIONS}

M.A.R. was involved in the data collection and analysis, drafting of the initial manuscript. D.J.P. was involved in the data analysis and critical revision of the manuscript. M.R.B.V. was involved in the data collection and critical revision of the manuscript. D.M.U. was involved in the study design and data collection, manuscript preparation, and critical revision. All authors have read and approved the final manuscript.

\section{ADDITIONAL INFORMATION}

Competing interests: The authors declare no competing interests.

Publisher's note: Springer Nature remains neutral with regard to jurisdictional claims in published maps and institutional affiliations.

\section{REFERENCES}

1. Bradley, B. J. \& Greene, A. C. Do health and education agencies in the United States share responsibility for academic achievement and health? A review of 25 years of evidence about the relationship of adolescents' academic achievement and health behaviors. J. Adolesc. Health 52, 523-532 (2013).

2. Donnelly, J. E. et al. Physical activity, fitness, cognitive function, and academic achievement in children: a systematic review. Med. Sci. Sports Exerc. 48, 1197-1222 (2016).

3. Petrides, K. V., Chamorro-Premuzic, T., Frederickson, N. \& Furnham, A. Explaining individual differences in scholastic behaviour and achievement. Br. J. Educ. Psychol. 75, 239-255 (2005).

4. French, M. T., Homer, J. F., Popovici, I. \& Robins, P. K. What you do in high school matters: high school GPA, educational attainment, and labor market earnings as a young adult. East. Econ. J. 41, 370-386 (2015).

5. Lê-Scherban, F., Diez Roux, A. V., Li, Y. \& Morgenstern, H. Does academic achievement during childhood and adolescence benefit later health? Ann. Epidemiol. 24, 344-355 (2014).

6. Liang, J., Matheson, B. E., Kaye, W. H. \& Boutelle, K. N. Neurocognitive correlates of obesity and obesity-related behaviors in children and adolescents. Int. J. Obes. 38, 494-506 (2014).

7. Horowitz-Kraus, T. \& Hutton, J. S. Brain connectivity in children is increased by the time they spend reading books and decreased by the length of exposure to screen-based media. Acta Paediatr. 107, 685-693 (2017).

8. Carson, V. et al. Systematic review of sedentary behaviour and health indicators in school-aged children and youth: an update. Appl. Physiol. Nutr. Metab. 41, S240-S265 (2016).

9. Carskadon, M. A. Sleep's effects on cognition and learning in adolescence. Prog. Brain Res. 190, 137-143 (2011).

10. Dewald, J. F., Meijer, A. M., Oort, F. J., Kerkhof, G. A. \& Bogels, S. M. The influence of sleep quality, sleep duration and sleepiness on school performance in children and adolescents: A meta-analytic review. Sleep. Med. Rev. 14, 179-189 (2010).

11. Kim, S. Y. et al. Dietary habits are associated with school performance in adolescents. Medicine 95, e3096 (2016).

12. Marques, A., Santos, D. A., Hillman, C. H. \& Sardinha, L. B. How does academic achievement relate to cardiorespiratory fitness, self-reported physical activity and objectively reported physical activity: a systematic review in children and adolescents aged 6-18 years. Br. J. Sports Med. 52, 1039 (2018).

13. Álvarez-Bueno, C. et al. Academic achievement and physical activity: a metaanalysis. Pediatrics 140, e20171498 (2017).

14. Faught, E. L. et al. The combined impact of diet, physical activity, sleep and screen time on academic achievement: a prospective study of elementary school students in Nova Scotia, Canada. Int. J. Behav. Nutr. Phys. Act. 14, 29 (2017).

15. Ickovics, J. R. et al. Health and academic achievement: cumulative effects of health assets on standardized test scores among urban youth in the United States*. J. Sch. Heal. 84, 40-48 (2014).

16. Martínez-Gómez, D. et al. Gender-specific influence of health behaviors on academic performance in Spanish adolescents: the AFINOS study. Nutr. Hosp. 27, 724-730 (2012).

17. Beltran-Valls, M. R., et al. Regular practice of competitive sports does not impair sleep in adolescents: DADOS Study. Pediatr. Exerc. Sci. 30, 229-236 (2018).

18. Cole, T. J., Bellizzi, M. C., Flegal, K. M., \& Dietz, W. H. Establishing a standard definition for child overweight and obesity worldwide: international survey. $B M J$ (Clinical Research Ed.), 320, 1240-1243 (2000).

19. Rey-López, J. P. et al. Sedentary patterns and media availability in European adolescents: The HELENA study. Prev. Med. 51, 50-55 (2010).

20. Royuela Rico, A. \& Macías Fernández, J. Propiedades Clinimétricas De La Versión Castellana Del Cuestionario De Pittsburg. Vigilia-Sueño 9, 81-94 (1997).

21. Buysse, D. J., Reynolds, C. F., Monk, T. H., Berman, S. R. \& Kupfer, D. J. The Pittsburgh sleep quality index: a new instrument for psychiatric practice and research. Psychiatry Res. 28, 193-213 (1989). 
Independent and combined influence of healthy lifestyle factors on... M Adelantado-Renau et al.

462

22. Jääskeläinen, A. et al. Associations of meal frequency and breakfast with obesity and metabolic syndrome traits in adolescents of Northern Finland Birth Cohort 1986. Nutr. Metab. Cardiovasc. Dis. 23, 1002-1009 (2013).

23. Léger, L. A., Mercier, D., Gadoury, C. \& Lambert, J. The multistage 20 metre shuttle run test for aerobic fitness. J. Sports Sci. 6, 93-101 (1988).

24. Esliger, D. W. et al. Validation of the GENEA accelerometer. Med Sci. Sport Exerc. 43, 1085-1093 (2011).

25. Phillips, L., Parfitt, G. \& Rowlands, A. Calibration of the GENEA accelerometer for assessment of physical activity intensity in children. J. Sci. Med. Sport. 16, 124-128 (2013).

26. Thurstone, L. L. \& Thurstone, T. G. TEA Test de Aptitudes Escolares (Scholar Aptitudes Test). 11th edn. (Ediciones TEA, S.A., Madrid, 2004).

27. Tanner, J. M. \& Whitehouse, R. H. Clinical longitudinal standards for height, weight, height velocity, weight velocity, and stages of puberty. Arch. Dis. Child. 51, 170-179 (1976).

28. Currie, C. et al. Researching health inequalities in adolescents: The development of the Health Behaviour in School-Aged Children (HBSC) Family Affluence Scale. Soc. Sci. Med. 66, 1429e1436 (2008).

29. Pan, L., Sherry, B., Park, S. \& Blanck, H. M. The association of obesity and school absenteeism attributed to illness or injury among adolescents in the United States, 2009. J. Adolesc. Health 52, 64-69 (2013).

30. Larsen, J. K., Kleinjan, M., Engels, R. C., Fisher, J. O. \& Hermans, R. C. Higher weight, lower education: a longitudinal association between adolescents' body mass index and their subsequent educational achievement level? J. Sch. Health 84, 769-776 (2014).

31. Carson, V. et al. Systematic review of sedentary behaviour and health indicators in school-aged children and youth: an update. Appl. Physiol. Nutr. Metab. 41 (6Suppl 3), S240-S265 (2016).
32. Gunnarsdottir, T., Njardvik, U., Olafsdottir, A. S., Craighead, L. W. \& Bjarnason, R. Teasing and social rejection among obese children enrolling in family-based behavioural treatment: effects on psychological adjustment and academic competencies. Int. J. Obes. 36, 35-44 (2012).

33. Kostyrka-Allchorne, K., Cooper, N. R. \& Simpson, A. The relationship between television exposure and children's cognition and behaviour: a systematic review. Dev. Rev. 44, 19-58 (2017).

34. Kim, S. Y., Kim, M. S., Park, B., Kim, J. H. \& Choi, H. G. The associations between internet use time and school performance among Korean adolescents differ according to the purpose of internet use. PLOS ONE 12, 1-14 (2017).

35. Benton, D. The influence of dietary status on the cognitive performance of children. Mol. Nutr. Food Res. 54, 457-470 (2010).

36. Shankar, P., Chung, R. \& Frank, D. A. Association of food insecurity with children's behavioral, emotional, and academic outcomes: a systematic review. J. Dev. Behav. Pediatr. 38, 135-150 (2017).

37. Chaddock, L., Pontifex, M. B., Hillman, C. H. \& Kramer, A. F. A review of the relation of aerobic fitness and physical activity to brain structure and function in children. J. Int. Neuropsychol. Soc. 17, 975-985 (2011).

38. Moore, R. D. et al. Aerobic fitness and intra-individual variability of neurocognition in preadolescent children. Brain Cogn. 82, 43-57 (2013).

39. Jackson, M. I. Understanding links between adolescent health and educational attainment. Demography 46, 671-694 (2009).

40. Brener, N. D., Billy, J. O. G. \& Grady, W. R. Assessment of factors affecting the validity of self-reported health-risk behavior among adolescents: evidence from the scientific literature. J. Adolesc. Health 33, 436-457 (2003).

41. Jiménez Pavón, D. et al. Socioeconomic status influences physical fitness in European adolescents independently of body fat and physical activity: the HELENA study. Nutr. Hosp. 25, 311-316 (2010). 